\title{
Control of crystal structure on solid acidity during smectite illitization
}

\author{
JIAZONG DU $^{1}$, JINGONG CAI ${ }^{1}$, QIAN CHAO ${ }^{1}$
}

${ }^{1}$ State Key Laboratory of Marine Geology, Tongji University, 200092 Shanghai, China

Solid acidity of smectite include Brønsted (B) and Lewis (L) acid sites, which is closely related to the crystal structure and can promote specific organic reactions due to their ability to denote or accept electrons. Smectite illitization is an important geological phenomenon in nature, which is accompanied with regulation of crystal structure. Therefore, the control of mineral structure on solid acidity during smectite illitization worth deeply investigation. Hydrothermal experiments were conducted at different temperatures to simulate smectite illitization. Then mineralogy and solid acidity were measured in different reaction stages.

Results showed that smectite converted into illite successfully and mix-layer minerals (MLMs) with different illitization degree were obtained. With increasing temperature, the transformation series was as follows: pure smectite to R0+R1 MLMs to R1+R $1_{\text {MPDO MLMs to R1 }}$ MPDO MLMs and finally to $\mathrm{R} 1_{\mathrm{MPDO}}+\mathrm{R} 2 \mathrm{MPDO}$ MLMs and quartz. Meanwhile, crystal morphology changed from smectite flakes to round lamella to polygonal particles. Furthermore, Ca decreased and $\mathrm{K}$ increased in interlayer region and substitution of $\mathrm{Al}$ for $\mathrm{Si}$ in tetrahedron was obvious. The intensity of vibrations at $3408 \mathrm{~cm}^{-1}$ and $1630 \mathrm{~cm}^{-1}$, which were ascribed to $-\mathrm{OH}$ of interlayer water and adsorbed water, respectively, decreased gradually. Solid acidity measurement showed that the total amount of acid decreased gradually, in which Bacid reached highest value at $250^{\circ} \mathrm{C}$ and $\mathrm{L}$ acid gradually decreased and a low value anomaly appeared at $250^{\circ} \mathrm{C}$.

Interlayer water content and dissociation capacity are two main factors to control variations of $\mathrm{B}$ acidity during smectite illitization. In the early stage, slightly reduction of interlayer water and increased interlayer charge promoted dissociation capacity, leading to increase of B acid. While massive reduction of interlayer water in the late stage determine the decrease of $\mathrm{B}$ acid. Variation of $\mathrm{L}$ acid was controlled by crystal structure. In the early stage, the imbalance of dissolution and recrystallization led to decrease of $\mathrm{Al}$ in octahedron, resulting in decrease of $\mathrm{Al}$ exposed to mineral edges and thus the decrease of $\mathrm{L}$ acid. In the late stage, the balance of dissolution and recrystallization enabled $\mathrm{L}$ acid increased at $300^{\circ} \mathrm{C}$. Then the increased crystallinity made the unsaturated $\mathrm{Al}^{3+}$ on the mineral edges could coordinate with hydroxy, leading to decrease in $\mathrm{L}$ acid. In addition, the formation of quartz at $450^{\circ} \mathrm{C}$ diluted the amount of $\mathrm{B}$ and $\mathrm{L}$ acid. 